\title{
Shape Memory and Superelasticity Goes Virtual!
}

Have you ever wanted to have all of the articles that focus on a specific topic easily accessible? Well now there's a way and it's available on the Shape Memory and Superelasticity Springer website.

Virtual issues allow you to see all of the articles on a specific subject in one place. It's a simple and easy way to save time. All it takes is three simple steps.

Step One. Find the virtual issues listing on the journal homepage (Fig. 1).
Step Two. Click on the virtual issue that contains articles that you are interested in viewing (Fig. 1).

Step Three. View the articles that are available in the virtual issue by accessing the scroll bar to the right of the list of articles (Fig. 2).

We hope you find this search option to be a valuable tool.

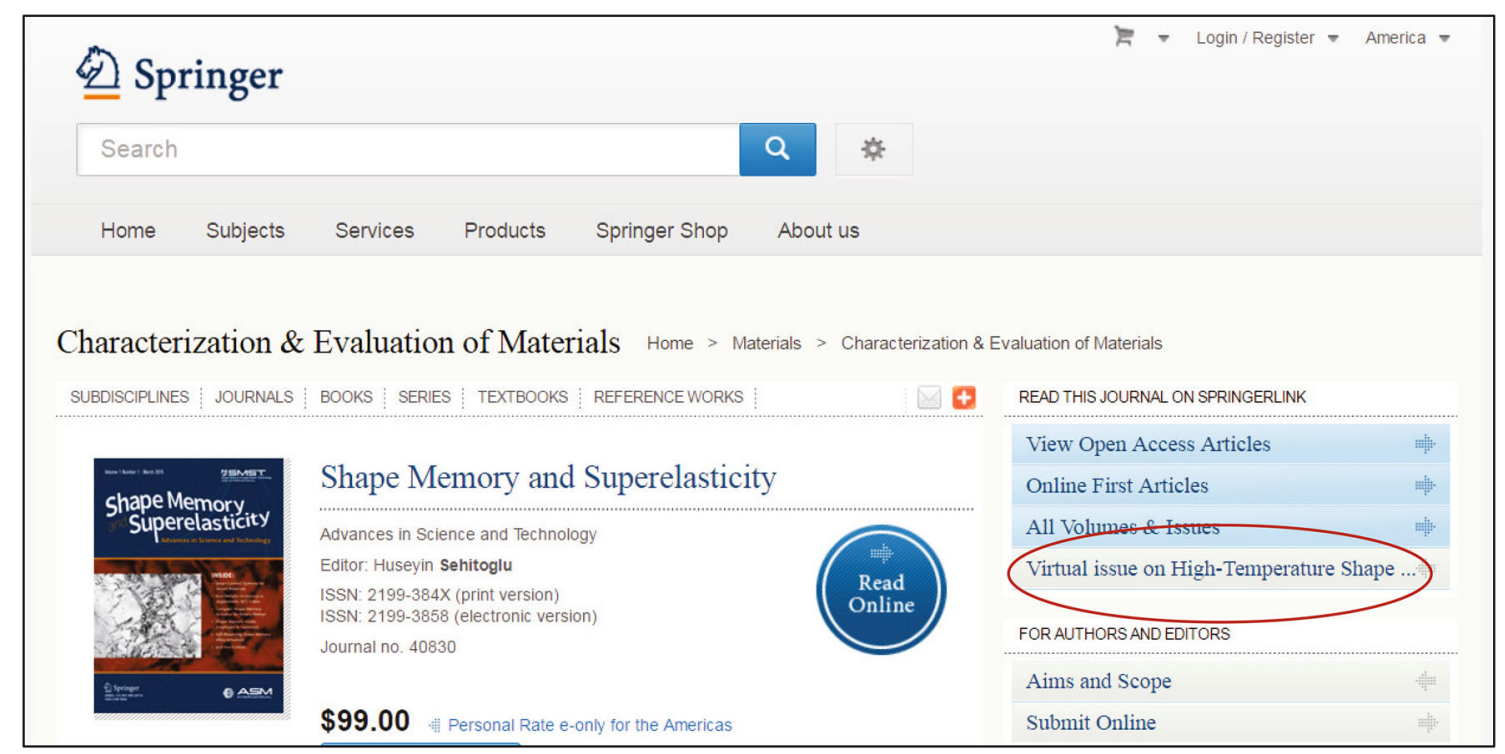

Fig. 1 Shape Memory and Superelasticity Home Page 
Fig. 2 Virtual article list

\section{Springer}

Search

Home

Subjects

Services

Products

Springer Shop

Q

하

Characterization \& Evaluation of Materials Home > Materials > characterization \&

SUBDISCIPLINES $\quad$ joURNALS $\quad$ BOOKS $\quad$ SERIES $\quad \vdots$ TEXTBOOKS $\quad$ REFERENCE WORKS

Virtual Issue on High-Temperature Shape Memory Alloys

A Focus on High-Temperature Shape Memory Alloys

Hans J. Maier

$[$ Read here

Directions for High-Temperature Shape Memory Alloys' Improvement: Straight Way to High-Entropy Materials?

G. S. Firstov, T. A. Kosorukova, Yu N. Koval, P. A. Verhovlyuk

$\triangle$ Read here

Effects of Grain Size and Co Addition on the Transformation Temperatures of Ti-Ni-Zr Thin Films

Akira Ishida

$[x$ Read here

Effect of Thermal Treatments on Ni-Mn-Ga and Ni-Rich Ni-Ti-Hf $/ \mathrm{Zr}$ High-Temperature Shape Memory Alloys

Ruben Santamarta, Alper Evirgen, Aquilina M. Perez-Sierra, Jaume Pons, Eduard Cesari, Ibrahim

Karaman, Ron D. Noebe

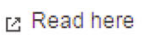

Computational Thermodynamics and Kinetics-Based ICME Framework for HighTemperature Shape Memory Alloys

Raymundo Arróyave, Anjana Talapatra, Luke Johnson, Navdeep Singh, Ji Ma, Ibrahim Karaman

$[$ Read here 